\title{
Perbandingan disfungsi seksual antara perempuan pengguna kontrasepsi oral dan kontrasepsi suntik
}

\author{
Nita Irawan Anugerah Pratama ${ }^{1}$, Pusparini ${ }^{2}$
}

\begin{abstract}
ABSTRAK
\section{LATAR BELAKANG}

Disfungsi seksual merupakan masalah dalam siklus respons seksual yang mengakibatkan individu gagal mendapatkan kepuasan dalam akivitas seksual. Disfungsi seksual meliputi berbagai gangguan dalam hubungan seksual, yang pada perempuan secara sederhana terbagi menjadi gangguan keinginan atau hasrat seksual, gairah, pelumasan, orgasme, kepuasan dan nyeri dalam hubungan seksual. Salah satu faktor penyebab terjadinya disfungsi seksual adalah efek samping dari penggunaan alat kontrasepsi hormonal. Penelitian ini bertujuan untuk mengetahui perbedaan disfungsi seksual pada pengguna kontrasepsi oral dan kontrasepsi suntik.
\end{abstract}

\section{METODE}

Penelitian ini menggunakan desain potong lintang. Sebanyak 132 perempuan yang terdiri dari 66 perempuan yang menggunakan kontrasepsi oral dan 66 yang menggunakan kontrasepsi hormonal berusia $15-49$ tahun yang memenuhi kriteria inklusi dan eksklusi diikutsertakan dalam penelitian ini. Penelitian dilakukan pada bulan April sampai dengan Juni 2019 di Puskesmas Kembangan Jakarta Barat. Untuk mengetahui adanya disfungsi seksual digunakan kuesioner Female Sexual Function Index (FSFI). Analisa statistik menggunakan uji Chi-square dengan nilai $\mathrm{p}<0.05$ berbeda bermakna.

\section{HASIL}

Rerata usia subjek penelitian pada pengguna kontrasepsi oral adalah $32.10 \pm 6.2$ tahun dan kontrasepsi suntik adalah $31.56 \pm 6.4$ tahun. Sebagian besar subjek mengalami disfungsi seksual sebanyak 73 orang (55.3\%). Kejadian disfungsi seksual pada pengguna kontrasepsi suntik lebih banyak dibandingkan dengan kontrasepsi oral yaitu sejumlah 52 orang $(78 \%)$ dengan nilai $\mathrm{p}=0.000$.

\section{KESIMPULAN}

Disfungsi seksual pada perempuan yang menggunakan kontrasepsi suntik lebih sering terjadi daripada pengguna kontrasepsi oral, sehingga pengguna kontrasepsi hormonal lebih baik menggunakan kontrasepsi oral dibandingkan kontrasepsi suntik untuk meminimalisasi kejadian disfungsi seksual.

Kata kunci : perempuan, disfungsi seksual, kontrasepsi oral, kontrasepsi suntik
${ }^{1}$ Program Studi Kedokteran, Fakultas Kedokteran, Universitas Trisakti

${ }^{2}$ Departemen Patologi Klinik, Fakultas Kedokteran, Universitas Trisakti

\section{Korespondensi:}

Pusparini

Departemen Patologi Klinik, Fakultas Kedokteran, Universitas Trisakti, Jalan Kyai Tapa No. 260, Grogol, Jakarta Barat 11440

Email: pusparini@trisakti.ac.id

J Biomedika Kesehat 2019;2(4):124129

DOI: 10.18051/JBiomedKes.2019. v2.124-129

pISSN: 2621-539X / eISSN: 2621-5470

Artikel akses terbuka (open access) ini didistribusikan di bawah lisensi Creative Commons Attribution 4.0 International (CC-BY 4.0) 


\begin{tabular}{c} 
ABSTRACT \\
\hline Comparison of sexual dysfunction between women using oral contraception and injection \\
contraception
\end{tabular}

\section{BACKGROUND}

Sexual dysfunction is a problem that occurs in the sexual response cycle caused individu fail to get satisfaction in the activity section. Sexual dysfunction compose of many factors at sexual interaction. In women, sexual dysfuntion divided into dysfunction of sexual desire, lubrication, orgasm and pain at sexual intercourse. One of the factors that cause sexual dysfunction is side effects after using hormonal contraceptive. The goal of this study was to compare sexual dysfunction between oral contraception users and injection contraception in women using contraception.

\section{METHODS}

This study was a cross sectional study at Puskesmas Kembangan West Jakarta from April to June 2019. A total of 132 women compose of 66 women using oral contraception and 66 women using injection contraception aged between 15-49 years old was included into the study. A Female Sexual Function Index (FSFI) questionaire was used to measure sexual disfunction of the subject. Statistical analysis using Chi-Square test with $\mathrm{p}$ value $<0.05$ as significantly different.

\section{RESULT}

The mean age of subjects using oral contraception were $32.10 \pm 6.2$ years old and injection contraception $31.56 \pm 6.4$ years old. Most of the subjects have experienced sexual dysfunction as many as 73 people (55.3\%). Subject using injection contraception have significance more sexsual disfunction compared to subject using oral contraception $(\mathrm{p}$ value $=0.000)$.

\section{CONCLUSION}

This study demonstrated that women using oral contraception have less sexual dysfunction compared to women using injection contraceptive. So, our suggestion were its better using oral contraceptive than injection contraceptive to minimizing sexual dysfunction.

Keywords : women, sexual dysfunction, oral contraceptive, injection contraceptive

\section{PENDAHULUAN}

Disfungsi seksual merupakan masalah yang terjadi dalam siklus respons seksual yang dapat mencegah individu untuk mendapatkan kepuasan dalam akivitas seksual. ${ }^{(1)}$ Pada PPDGJ III dan DSM-V, disfungsi seksual meliputi berbagai gangguan dalam hubungan seksual, dimana individu tidak mampu berperan serta dalam hubungan yang diharapkan. ${ }^{(2)}$ Gangguan dapat berupa kekurangan minat (interest), kenikmatan (enjoyment), gagal dalam respons fisiologi yang dibutuhkan untuk interaksi seksual yang efektif atau tidak mampu mengendalikan atau mengalami orgasme. Disfungsi seksual pada perempuan secara sederhana terbagi menjadi gangguan keinginan atau hasrat seksual, gairah, pelumasan, orgasme, kepuasan dan nyeri dalam hubungan seksual. ${ }^{(3)}$

Penelitian yang dilakukan pada 262 perempuan yang menggunakan kontrasepsi di sebelas kinik perawatan di Malaysia, mendapatkan bahwa prevalensi disfungsi seksual diantara para pengguna kontrasepsi sebesar $9.5 \%$ dengan disfungsi seksual tertinggi pada kepuasan seksual (29.8\%), gangguan hasrat seksual $(29.4 \%))^{(4)}$

Disfungsi seksual pada perempuan dapat disebabkan oleh berbagai macam faktor, salah satunya merupakan efek samping dari penggunaan alat kontrasepsi hormonal diantaranya implan, suntik maupun oral (pil). ${ }^{(5)}$ Hubungan antara kejadian disfungsi seksual dan penggunaan kontrasepsi masih diperdebatkan. Hal ini antara lain dapat dilihat dari penelitian Kariman et al. mendapatkanbahwaperempuanyangmenggunakan kontrasepsi suntik tiga bulanan memberikan efek terjadinya disfungsi seksual lebih tinggi daripada perempuan yang menggunakan kontrasepsi oral. (6) Penelitian Gabalci et al. menyimpulkan bahwa perempuan yang menggunakan kontrasepsi IUD, kondom, dan oral tidak memberikan efek negatif pada akivitas seksual.( ${ }^{(7)}$ Pada penelitian yang dilakukan oleh Ozgoli et al. dilaporkan terdapat perbedaan yang bermakna pada perempuan yang menggunakan kontrasepsi cyclofem (suntik satu bulanan) dan DMPA (suntik tiga bulanan) terhadap keinginan seksual dan nyeri dalam hubungan seksual. ${ }^{(8)}$ Adanya hasil-hasil penelitian yang belum konsisten sehingga masih memerlukan penelitian lebih lanjut untuk membandingkan disfungsi seksual antara perempuan pengguna kontrasepsi hormonal. Diantara kontrasepsi yang ada, kontrasepsi hormonal baik oral maupun suntik merupakan kontrasepsi yang paling banyak 
digunakan. ${ }^{(7)}$

Penelitian ini bertujuan untuk membandingkan disfungsi seksual antara perempuan yang menggunakan kontrasepsi oral dan kontrasepsi suntik 3 bulan.

\section{METODE}

Penelitian ini menggunakan desain potong lintang. Subjek penelitian adalah perempuan usia subur 15-49 tahun yang berkunjung di poli Keluaga Berencana (KB) pusat kesehatan masyarakat Kembangan Jakarta Barat. Penelitian dilaksanakan pada bulan April hingga Juni 2019. Besar sampel pada penelitian ini dihitung menggunakan rumus populasi infinit dengan nilai $\mathrm{Za}^{2}$ pada tingkat kemaknaan $95 \%$ besarnya 1.96; nilai $\mathrm{p}$ yaitu prevalensi penderita disfungsi seksual $0.095^{(4)}$, nilai q yaitu prevalensi yang tidak menderita disfungsi seksual (1-p), dan nilai d yaitu akurasi dari pengukuran yang besarnya 0.05 . Dari rumus tersebut didapatkan besar sampel adalah 132 perempuan yang terdiri dari 66 perempuan pengguna kontrasepsi oral dan 66 pengguna kontrasepsi suntik setelah ditambah antisipasi drop out sebesar $15 \%$. Kriteria inklusi dalam penelitian ini adalah perempuan usia subur 15-49 tahun, telah menggunakan kontrasepsi oral atau kontrasepsi suntik 3 bulanan selama $>6$ bulan secara terus-menerus tanpa jeda, sudah menikah, masih aktif dalam hubungan seksual, dan bersedia untuk ikut serta dalam penelitian dengan menanda tangani informed consent. Kriteria eksklusi adalah menopause, mengonsumsi obat antidepresan, antihipertensi, dan antihistamin serta kesulitan berkomunkasi.

Pengambilan sampel dalam penelitian ini adalah consecutive sampling dengan menggunakan kuesioner Female Sexual Function Index (FSFI) ${ }^{(3)}$ untuk menilai disfungsi seksual. Kuesioner FSFI terdiri dari 6 domain yaitu domain keinginan, gairah, lubrikasi, orgasme, kepuasan, dan nyeri dalam berhubungan dengan 19 pertanyaan yaitu 2 pertanyaan mengenai dorongan seksual; faktor pengali $0.6,4$ pertanyaan mengenai bangkitnya keinginan seksual; faktor pengali $0.3,4$ pertanyaan mengenai lubrikasi; faktor pengali $0.3,3$ pertanyaan mengenai orgasme; faktor pengali 0.4 , 3 pertanyaan mengenai kepuasan seksual; faktor pengali $0.4,3$ pertanyaan mengenai nyeri pada hubungan seksual; faktor pengali 0.4 . Selanjutnya hasil jumlah perhitungan dikalikan dengan faktor pengali, apabila skor $\leq 26.55$ dapat dikategorikan sebagai disfungsi seksual. Penelitian ini telah lolos kaji etik dari Komisi Etik Riset Fakultas Kedokteran Universitas Trisakti dengan nomor kaji etik 17/KER-FK/I/2019. Analisa statistik menggunakan uji Chi Square dengan nilai $\mathrm{p}<0.05$ berbeda bermakna.

\section{HASIL}

Tabel 1. Karakteristik subjek penelitian

\begin{tabular}{lc}
\hline Karakteristik & $\mathbf{n}(\mathbf{\%})$ \\
\hline Usia $(\mathrm{X} \pm \mathrm{SD})$-tahun & $32.10 \pm 6.2$ \\
Kontrasepsi oral & $32.64 \pm 6.1$ \\
Kontrasepsi suntik & $31.56 \pm 6.4$ \\
Kontrasepsi & \\
Oral & $66(50)$ \\
Suntik & $66(50)$ \\
Fungsi seksual & \\
Disfungsi $(\leq 26.55)$ & $73(55.3)$ \\
Tidak disfungsi $(>26.55)$ & $59(44.7)$ \\
Hasil FSFI (X+SD) & \\
Kontrasepsi oral & $25.9 \pm 3.6$ \\
Domain keinginan & $4.57 \pm 3.9$ \\
Domain gairah & $4.3 \pm 0.6$ \\
Domain lubrikasi & $4.5 \pm 0.6$ \\
Domain orgasme & $4.6 \pm 0.5$ \\
Domain kepuasan & $4.5 \pm 0.7$ \\
Domain nyeri & $4.2 \pm 0.9$ \\
Kontrasepsi suntik & $22.9 \pm 4.1$ \\
Domain keinginan & $4.2 \pm 0.4$ \\
Domain gairah & $3.8 \pm 0.9$ \\
Domain lubrikasi & $3.9 \pm 0.9$ \\
Domain orgasme & $3.9 \pm 0.9$ \\
Domain kepuasan & $3.6 \pm 0.9$ \\
Domain nyeri & $3.8 \pm 0.9$ \\
\hline
\end{tabular}

Tabel 1 memperlihatkan rerata usia subjek adalah $32.1 \pm 6.2$ tahun. Wanita yang mengalami disfungsi seksual berdasarkan FSFI score sebanyak 73 orang $(55.3 \%)$. Rerata hasil nilai FSFI untuk kedua kontrasepsi baik oral maupun suntik sama-sama mengalami penurunan yaitu $\leq$ 26.55 dan dari seluruh domain nilai FSFI terendah adalah pada domain keinginan (pengali 0.6).

Tabel 2 memperlihatkan perempuan pengguna kontrasepsi suntik sebanyak 52 (78.8\%) lebih banyak secara bermakna mengalami disfungsi seksual dibandingkan dengan perempuan pengguna kontrasepsi oral sebanyak 21 (31.8\%) $(\mathrm{p}=0.000)$.

\section{PEMBAHASAN}

Disfungsi

ketidakmampuan respons seksual seksual merupakan individu untuk mencapai maksimal selama aktivitas 
Tabel 2. Perbandingan disfungsi seksual antara pengguna kontrasepsi oral dan kontrasepsi suntik

\begin{tabular}{|c|c|c|c|c|c|}
\hline \multirow{3}{*}{ Kontrasepsi } & \multicolumn{4}{|c|}{ Fungsi Seksual } & \multirow{3}{*}{ Nilai $\mathrm{p}$} \\
\hline & \multicolumn{2}{|c|}{ Disfungsi seksual } & \multicolumn{2}{|c|}{ Tidak disfungsi seksual } & \\
\hline & $\mathrm{n}$ & $\%$ & $\mathrm{n}$ & $\%$ & \\
\hline Oral & 21 & 31.8 & 45 & 68.2 & \multirow[t]{2}{*}{$0.000^{*}$} \\
\hline Suntik & 52 & 78.8 & 14 & 21.2 & \\
\hline
\end{tabular}

*Uji Chi-Square, $\mathrm{p}<0.05$ berbeda bermakna

seksual. ${ }^{(9)}$ Respons seksual secara umum dibagi menjadi excitement, plateu, orgasme, dan resolusi. Secara sederhana respons seksual terbagi menjadi gangguan keinginan, gairah, lubrikasi, orgasme, kepuasan dan nyeri berhubungan seksual. ${ }^{(3)}$

Pada penelitian ini, tingginya kejadian disfungsi seksual pada perempuan pengguna kontrasepsi suntik dibandingkan kontrasepsi oral sesuai dengan penelitian Kariman et al perempuan yang mengalami disfungsi seksual lebih tinggi pada pengguna kontrasepsi suntik dibandingkan kontrasepsi oral. ${ }^{(6)}$ Penelitian yang dilakukan pada 240 responden menunjukkan terdapat disfungsi seksual yang berbeda bermakna antar subjek terutama pada status pernikahan dan siklus menstruasi. Lamanya pernikahan dan siklus menstruasi berpengaruh pada terjadinya disfungsi seksual wanita. ${ }^{(8)}$ Lamanya status pernikahan berhubungan terhadap terjadinya disfungsi seksual, ini berkaitan pada berbagai faktor seperti pendapatan, pekerjaan, kesehatan anak. Hal tersebut berpengaruh pada bagaimana pasangan berkomunikasi satu sama lain sehingga memengaruhi kepuasaan dalam pernikahan serta kemampuan dalam melakukan hubungan seksual. ${ }^{(10)}$ Siklus menstruasi berpengaruh akibat terjadinya perubahan hormon dari penggunaan kontrasepsi sehingga menyebabkan siklus menstruasi terganggu, pada umumnya pengguna kontrasepsi suntik tidak mengalami menstruasi selama 3 bulan berturut-turut (saat tubuh masih dalam pengaruh hormon kontrasepsi) yang menimbulkan pada ketidakinginan dan gangguan gairah dalam melakukan hubungan seksual bersama pasangan. (11) Hal ini juga sejalan dengan penelitian yang dilakukan Marlinda yang menyatakan bahwa kontrasepsi suntik DMPA lebih memberikan efek terjadinya disfungsi seksual dibandingkan dengan kontrasepsi lain seperti alat kontrasepsi dalam rahim (AKDR), kontrasepsi hormonal oral dan kontrasepsi implan. Selain itu kontrasepsi suntik 3 bulanan mengandung hormon progesteron yang efek kerjanya adalah antiesterogenik sehingga kerja estradiol berkurang dan berakibat terjadinya disfungsi seksual. ${ }^{(12)}$ Pada wanita yang menggunakan kontrasepsi suntik, kadar estrasdiol menurun dan terjadi penekanan estrogen dan dilaporkan 5.8\% mengalami penurunan keinginan seksual. $^{(13)}$ Kontrasepsi suntik berisi progesteron yang memiliki peran utama untuk mencegah ovulasi dengan kadar progestin yang tinggi akan menghambat lonjakan Luteinizing Hormone (LH) secara aktif dalam merangsang proses ovulasi dan pemakaian dalam jangka panjang menyebabkan gangguan fungsi seksual. ${ }^{(14)}$

Perubahan fungsi seksual pada pengguna kontrasepsi oral terjadi setelah penggunaan selama lebih dari 3 bulan. Penggunaan kontrasepsi oral memberikan dampak terjadinya kekeringan vagina dan penurunanan dalam lubrikasi, yang tentunya memengaruhi fungsi seksual seorang perempuan. (15,16) Perempuan lebih rentan mengalami disfungsi seksual dari pada pria. Berdasarkan kenyataan yang ada, hubungan seksual untuk perempuan adalah pusat kualitas hidup dan menggambarkan aspek psikososial. Terdapat beberapa faktor yang dapat memengaruhi fungsi seksual selain hormonal adalah kesehatan, masalah emosional, stres dan hubungan interpersonal serta budaya. ${ }^{(8)}$

Tingginya kejadian disfungsi seksual pada perempuan pengguna kontrasepsi suntik dibanding dengan perempuan pengguna kontrasepsi oral harus mendapatkan perhatian khusus kepada masyarakat pada umumnya dan petugas kesehatan pada khususnya karena disfungsi seksual dapat memengaruhi hubungan dengan keluarga dan dapat menurunkan kualitas hidup seseorang. Hal ini menggambarkan faktor medis, psikologis, khususnya sosio ekonomi, perbedaan budaya, ras serta hubungan antar pasangan dan tingkat 
pendidikan memengaruhi kualitas seksual. ${ }^{(17,18)}$

Penurunan fungsi seksual pada penelitian ini terutama pada keinginan seksual dan subjek hanya merasa pasrah dengan keadaan yang dirasakan serta tidak melakukan usaha untuk mengatasi atau mencari solusi karena masih merasa malu dan tabu untuk mendiskusikan masalah seksual dengan dokter atau tenaga medis lainnya. Pengaruh sosial budaya dan kurangnya pengetahuan dapat juga menyebabkan wanita malu untuk mendiskusikan masalah seksualnya, padahal sikap malu ini dapat menyebabkan wanita mengalami depresi. ${ }^{(19)}$

Pengalaman yang menyenangkan dan perasaan yang bahagia terhadap pasangan dapat memengaruhi aktivitas seksual. Kehidupan seksual yang memuaskan serta pengalaman dan fungsi seksual yang positif mengenai dirinya akan berdampak pada kesejahteraan hidup dalam berkeluarga. ${ }^{(20)}$ Pada pelaksanaan penelitian ini, terdapat beberapa keterbatasan dalam penelitian diantaranya adalah penelitian ini tidak membandingkan fungsi seksual pada saat sebelum menggunakan kontrasepsi, hubungan interpersonal, dan tidak meneliti faktor-faktor lain yang dapat memengaruhi aktivitas seksual seperti, lama penggunaan kontrasepsi, siklus menstruasi, status penikahan, stres. Penggunaan kontrasepsi hormonal baik kontrasepsi oral maupun suntik dapat mengakibatkan penurunan/gangguan fungsi seksual sehingga bila seorang perempuan ingin menggunakan kontrasepsi perlu dipertimbangkan lagi mengenai kemungkinan untuk mencari kontrasepsi selain kontrasepsi hormonal baik oral, suntik maupun implan untuk mencegah/ mengurangi kejadian disfungsi seksual yang dapat mengakibatkan penurunan keharmonisan rumah tangga.

\section{KESIMPULAN}

Disfungsi seksual pada pengguna kontrasepsi suntik lebih banyak dibandingkan pada pengguna kontrasepsi oral.

\section{UCAPAN TERIMA KASIH}

Peneliti mengucapkan terima kasih kepada Kepala Puskesmas dan seluruh staf Puskesmas Kembangan Jakarta Barat serta seluruh subjek penelitian yang bersedia menjadi responden penelitian ini.

\section{KONFLIK KEPENTINGAN}

Peneliti menyatakan tidak ada konflik kepentingan

\section{REFERENSI}

1. Chen $\mathrm{CH}$, Lin YC, Chiu LH, Chu YH, Ruan FF, Liu WM, et al. Female sexual dysfunction: definition, classification, and debates. Taiwan J Obstet Gynecol 2013;52:3-7.http://dx.doi. org/10.1016/j.tjog.2013.01.002.

2. Maslim, Rusdi. Diagnosis gangguan jiwa rujukan. In: PPDGJ - III dan DSM-V. 2nd ed. Jakarta:FK-Unika Atmajaya;2013.p.96-7.

3. Neijenhuijs K, Hooghiemstra N, Holtmaat $\mathrm{K}$, et al. The female sexual function index (FSFI)- A systematic review of measurement properties. J Sex Med 2019;16(5):640-60. Doi:10.1016/j.jsxm.2019.03.001.

4. Adibah HI, Hafizah MS, Ching SM. Female sexual dysfunction among contraceptive user in Malaysia. Madridge J Woman Health Eman 2017;1:36-40.

5. Burrows LJ, Basha M, Goldstein AT. The effects of hormonal contraceptives on female sexuality: A review. J Sex Med 2012;9:221323. DOI:10.1111/j.1743-6109.2012.02848.x

6. Kariman N, Sheikhan Z, Simbar M, Zahiroddin A, Bahgban AA. Sexual dysfunction in two types of hormonal contraception: combined oral contraceptives versus depot medroxyprogesterone acetate. J Midwifery Reproduction Health 2017;5:806-13. DOI: 10.22038/jmrh.2016.7763.

7. Gabalci E, Terzioglu F. The effect of family planning methods used by women reproductive age on their sexual life. Sex Disabil 2010;28:275-85.DOI 10.1007/s11195010-9161-9.

8. Ozgoli G, Sheikhan Z, dolatian M, Simbar M, Bakhtyari M, Nasiri M. Comparison of sexual dysfunction in women using depot medroxyprogesterone acetate (DMPA) and cyclofem. J Reprod Infertil 2015;16:102-8.

9. Bachman G, Stern L, Ramos J. Female sexual function. Women's Med 2008;1-5. DOI 10.3843/GLOWM.10429.

10. Khazaei M, Rostami R, Zaryabi A. The relation between sexual dysfunction and marital satisfaction in Iranian married students. Procedia Soc Behavioral Sci 2011;30:783-85. doi:10.1016/j.sbspro.2011.10.152. 
11. Caruso S, Agnello C, Malandrino C, et al. Do hormones influence women's sex? Sexual acitivity over the menstrual cycle. J Sex Med 2014;11:211-21. DOI:10. 1111/jsm.12348.

12. Roza marlinda. Hubungan persepsi wanita usia subur iud di wilayah kerja Puskesmas Lintaubuo III Kabupaten tanah datar tahun 2010. Repro Unand 2011;1:202-8.

13. De Castro Coelho F, Barros C. The potential of hormonal contraception to influence female sexuality. Int J Repro Med 2019. ID 9701384. Doi.org/10.1155/2019/9701384.

14. Smith NK, Jozkowski KN, Sanders SA. Hormonal contraception and female pain, orgasm and sexual pleasure. J Sex Med 2014;11:462-70.

15. Higgins JA, Smith NK. The Sexual Acceptability of Contraception: Reviewing the Literature and Building a New Concept. J Sex Res 2016;53:417-56. DOI: 10.1080/00224499.2015.1134425.

16. Zimmerman Y1, Eijkemans MJ, Coelingh Bennink HJ, Blankenstein MA, Fauser BC. The effect of combined oral contraception on testosterone levels in healthy women: a systematic review and meta-analysis. Hum Reprod Update 2014;20:76-105.

17. Umran O. Effect of the contraceptive methods on female sexual function. International $J$ of Caring Science 2016:112-18.

18. Casado-Espada NM, de Alarcón R, de la Iglesia-Larrad JI, Bote-Bonaechea B, et al. Hormonal Contraceptives, Female Sexual Dysfunction, and Managing Strategies: A Review. J Clin Med 2019;8:908.doi:10.3390/ jem8060908.

19. Vural EZ, Gonenc I. Contraception and sexuality. Turkish Family Physician 2011;2:21-3.

20. Benagiano G, Carrara D, Fillipi V. Sex and reproductions : an evolving relationship. Human Repro Update 2010;16:96-107. doi:10.1093/humupd/dmp028. 